\title{
Sensing materials with a concurrent sensitivity: design, synthesis and application in multisensory systems
}

\author{
Larisa Lvova $^{\mathrm{a}}$, Giuseppe Pomarico ${ }^{\mathrm{a}}$, Igor Spiridonov ${ }^{\mathrm{b}}$, Olga Mednova ${ }^{\mathrm{b}}$, \\ Dmitry Kirsanov ${ }^{\mathrm{b}}$, Andrey Legin ${ }^{\mathrm{b}}$, Corrado Di Natale ${ }^{\mathrm{c}}$, Arnaldo D'Amico ${ }^{\mathrm{c}}$ \\ and Roberto Paolesse ${ }^{a}$ \\ a Department of Chemical Sciences and Technologies, University "Tor Vergata”, Rome, Italy \\ ${ }^{b}$ Chemistry Department, St. Petersburg State University, St. Petersburg, Russia \\ c Department of Electronic Engineering, University "Tor Vergata”, Rome, Italy
}

\begin{abstract}
A series of novel sensing materials with concurrent sensitivity, namely the porphyrins [free-base, $\mathrm{Mn}(\mathrm{III})$ and $\mathrm{Fe}(\mathrm{III})$ complexes], functionalized with crown-ether or aza-crown (cyclam) pendant groups, were synthesized and tested as ionophores for polymeric membrane electrodes. Several aspects were studied in order to evaluate the functionality and the desired sensitivity of resulting crown-porphyrins hyphenated ionophores, among them the nature and the size of crown fragment cavity, the length of the alkyl pendant incorporating the crown-ether unit, the presence and the nature of central metal ion both in porphyrin and crown macrocycles.
\end{abstract}

Keywords: crown-porphyrin ionophores, concurrent sensitivity, potentiometric sensor array PACS: 07.05.Fb, 07.05.Kf, 07.07.Df

\section{INTRODUCTION}

The design of new ionophores with analytically useful selectivity remains until now a formidable challenge. The use of ligands with the cavity of determined size, like has permitted to develop highly selective potentiometric sensors [1]. The combination of two sensitive compartments such as free-base porphyrin and crownether in single ionophore molecule may significantly improve the resulting cationic sensor selectivity due to the synergetic complexing effect of the ionophore. On the other hand the metallation of the porphyrin unit of hyphenated crown-porphyrin composite, besides the possible improvement of anionic selectivity of the ionophore, may evoke the concurrent sensitivity towards both anionic and cationic species, Fig.1.

\section{RESULTS AND DISCUSSION}

Crown-porphyrins were recently applied mainly for optic sensors development, but their utility in potentiometric cross-sensitive sensors was not studied [2]. For this reason we have tested the performance of PVC/oNPOE membrane electrodes containing hyphenated crown-porphyrin ionophores. The electrodes doped with Mn-

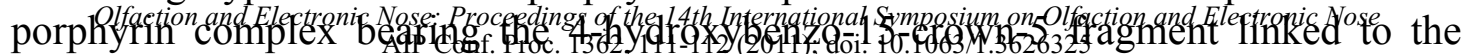

(c) 2011 American Institute of Physics 978-0-7354-0920-0/\$30.00 
porphyrin via the rigid $-\mathrm{N}=\mathrm{N}$ - bond exhibited a prevalent anionic sensitivity for all the tested analytes.
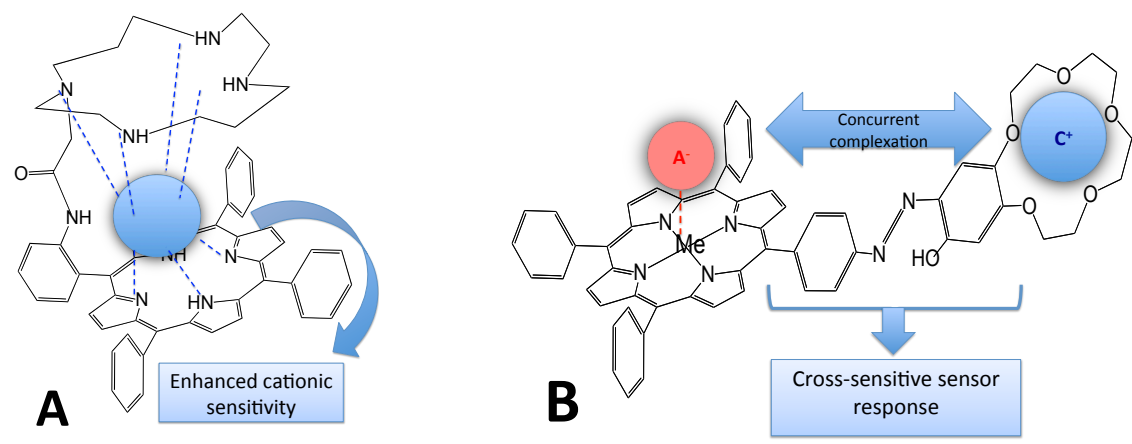

FIGURE 1. (A) An enhancing of cationic selectivity, (B) a schematic presentation of the concurrent complexation of cationic and anionic species by crown-porphyrins.

When Mn was substituted with Fe ion, the concurrent complexation was reversed and the crown-Fe-porphyrin conjugates recognized the low concentrations of cations more efficiently, while the growth of the analyte concentration resulted in the switch from cationic to anionic sensitivity, as it is shown in Fig.2A. The incorporation of azacrown (cyclam) compartments in Mn and Fe porphyrins via more flexible amide link resulted again in a prevalent anionic selectivity of cyclam-(Mn-porphyrin) conjugates, while the well defined cationic response towards transition metal ions was detected for cyclam-(Fe-porphyrin) ionophore, Fig.2B.
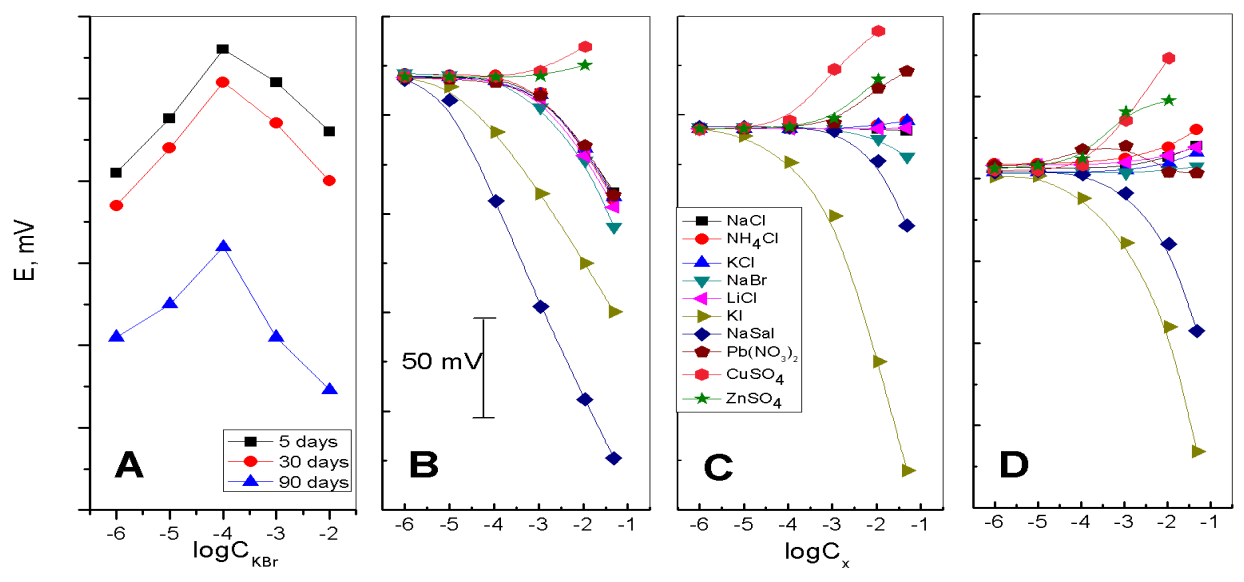

FIGURE 2. (A) The repetitive potentiometric responses of 15-crown-5-funczionalized Feporphyrin towards $\mathrm{KBr}$ aqueous solutions in range from $10^{-6}$ to $10^{-2} \mathrm{~mol} / \mathrm{L}$; Potentiometric responses of (B) cyclam, (C) cyclam-(Mn-porphyrin) and (D) cyclam-(Fe-porphyrin) containing polymeric membrane electrodes towards aqueous solutions of several salts.

\section{REFERENCES}

1. E. Bakker, P. Bühlmann, E. Pretsch, Chem. Rev. 98, 1593-1687 (1998)

2. P. Even, B. Boitrel, Coord. Chem. Rev. 250, 519-541 (2006) 
Copyright of AIP Conference Proceedings is the property of American Institute of Physics and its content may not be copied or emailed to multiple sites or posted to a listserv without the copyright holder's express written permission. However, users may print, download, or email articles for individual use. 